\title{
Efficiency of mobile eye camps for providing combined eye and vision care in underserved areas in Uttarakhand
}

\author{
Siegfried Wahl1,2,*, Alexander Leube ${ }^{1,2}$, Renu Dhasmana ${ }^{3}$, Premjeeth Moodbidri ${ }^{4}$, Vasuki \\ Krishna Kumar, Nitin Sisodia ${ }^{5}$, Joachim Kuss ${ }^{2}$ \\ 1 Institute for Ophthalmic Research, Eberhard Karls University, Elfriede-Aulhorn-Str. 7, Tuebingen 72076, \\ Germany \\ 2 Carl Zeiss Vision International GmbH, Turnstr. 27, Aalen 73430, Germany \\ 3 Department of Ophthalmology, Himalayan Institute of Medical Science, Dehradun 248140, India \\ 4 Carl Zeiss India Pvt. Ltd, Plot No.3, Jigani Link Road, Bangalore 560099, India \\ 5 Sohum Innovation Lab, Whitefield, Bangalore 560066, India \\ * Correspondence: siegfried.wahl@uni-tuebingen.de
}

\begin{abstract}
To report eye examinations findings and cost-efficiency of mobile eye and vision care screening in underserved areas in north India. The Aloka Vision Program combines optometrical and ophthalmological screening as mobile eye camps with organized referrals to local eye hospitals. 402 people from urban $(\mathrm{N}=191)$ and rural $(\mathrm{N}=211)$ areas in the district of Uttarakhand, India, were screened for refractive error (RE), visual acuity (VA) and eye health. Statistical analysis was performed using ANOVA model and odd ratios. Costs were estimated based on the expenses of the camps. $44 \%$ of the participants were male and $56 \%$ were female and the age ranged from 7 to 72 years (urban) and 7 to 80 years (rural). Lack of accessibility of eye care was mentioned by $10 \%$ of the urban and $47 \%$ of the rural participants, why not attending regular vision test. Mild and severe visual impairment $\mathrm{VA}<0.5 \log \mathrm{MAR}$ affected every fifth person, independent from the living environment. RE showed a myopic trend for the urban environment $(\Delta \mathrm{M}=0.67 \mathrm{D}, \mathrm{p}=0.11)$. The risk for blindness was three times higher in rural compared to the urban area, mainly caused by cataract. The major costs are given by the treatments $(58 \%)$, followed by mobilization and organization $(\sim 30 \%)$, whereas personal costs are low ( 11\%). Combined eye and vision care models reduce costs for separated screening's organization and thus can increase the effectiveness of eye screening programs significantly.
\end{abstract}

Keywords: Eye care | Vision screening | India | Aloka Vision Program

\section{Introduction}

Globally, the leading causes of visual impairment are uncorrected refractive error (43\%)1 and cataract (33\%).[1] These two eye health related conditions are easily treatable by simple glasses or standard surgery resulting in at least $75 \%$ of preventable cases of blindness.[2] Prevalence data for India from 2010 revealed that 133 million people, including 11 million children, are affected by visual impairment or blindness.[3] According to the World Health Organization (WHO), these are the second highest numbers in the world.1 Under the consideration of the WHO program "VISION 2020: The Right to Sight",[4] focused screening programs can increase the awareness of visual impairment and blindness and further improve the availability of vision care service [5] to eliminate avoidable

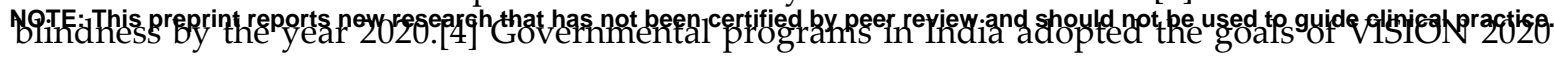
aim in the twelfth five year plan to establish 5,000 vision centers for primary eye care by 2017 which 
medRxiv preprint doi: https://doi.org/10.1101/2020.10.27.20217000; this version posted November $1,2020$. The copyright holder for this preprint (which was not certified by peer review) is the author/funder, who has granted medRxiv a license to display the preprint in

perpetuity.
It is made available under a CC-BY 4.0 International license.

serve as local first interface points.[6] Additionally, to these programs, initiatives from nongovernmental organizations (NGOs) and the private sector can enhance the efficacy and reachability of eye care services.[6] Mobile eye care programs like the "Nayantara" project from Tirupati Eye Centre [7] uses traveling specialists to diagnose and treat eye conditions, e.g. diabetic retinopathy. Tele-Ophthalmology approaches as the Aravind Tele-Ophthalmology Network [8] or the Sankara Netralaya Tele-Ophthalmology Project [9] can further improve primary eye care with keeping patient satisfaction high, especially in rural areas.[10] Effectiveness and reliability of tele-ophthalmogy models were shown for the detection of diabetic retinopathy [11] but seem to be not appropriate for determination of refractive errors. Next to an increase in efficiency and availability of primary eye care services, there is a further need on trained and educated specialists which could provide this eye care services.[12]

The Aloka Vision Programme screening scheme, shown in Figure 1, combines a training of local entrepreneurs with the availability of primary eye care in providing ophthalmologic and optometric screening with an end-to-end support of dispensing spectacles or medical eye care. The focus is on an autonomous and self-energizing process to establish eye camps and vision correction for underprivileged people. The current study reports on frequency estimations of refractive errors and eye health conditions and compares cost-efficiency of a combined eye and vision care services in underserved areas in India.
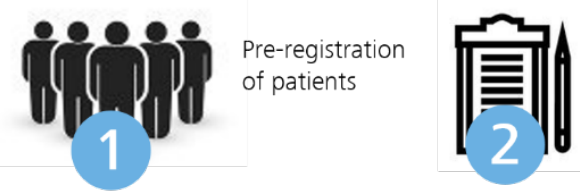

Patient registration

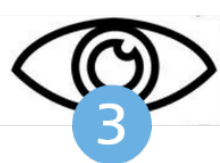

Exam of anterior eye

Retina screening (Ophthalmoscopy)

Eye doctor's recommendation

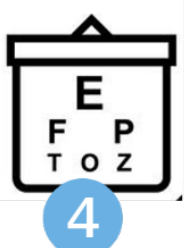

Vision test

Near vision test with

presbyopes

Prescription

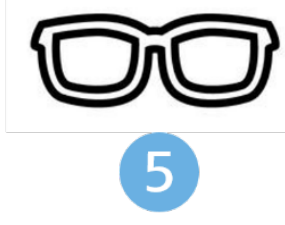

Frame selection and order confirmation for patients with glasses

Referral to eye clinic at Himalayan Institute for cataract / medical patients

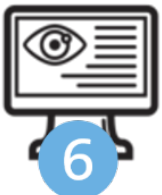

Check completion of data before patient leaves

Figure 1: The Aloka Vision Programme screening scheme

\section{Materials and Methods}

\section{Participants and Public Involvement}

The current study reports on vision screenings and their associated costs on behalf of the Aloka Vision Program carried out in June 2018 in the northern India State of Uttarakhand. Vision screening was performed by setting up mobile eye camps in an urban area (Dehradun city, $450 \mathrm{~m}$ above sea height) and in a rural area (Mussoorie, 2,000 $\mathrm{m}$ above sea height). Each eye camp included one to two optometrists from Carl Zeiss India Pvt. Ltd, one ophthalmologists from the Department of Ophthalmology, Himalayan Institute of Medical Science, volunteers from local NGOs and supporting stuff. The eye camps were open for everybody and free of charge. The study design follows prospective, cross-section, case-finding screening program.[13] 
medRxiv preprint doi: https://doi.org/10.1101/2020.10.27.20217000; this version posted November 1 , 2020. The copyright holder for this preprint (which was not certified by peer review) is the author/funder, who has granted medRxiv a license to display the preprint in

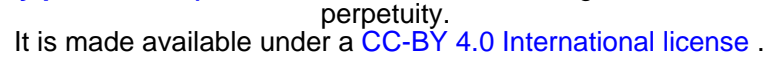

\section{Screening Protocol}

Prior to the participation in the study, the screening protocol included an informed consent which was provided to the participants or in case of age under 18 by a parent or legal guardian. Further, the rationales of the study in accordance with the Declaration of Helsinki. Ethical considerations were ensured, since the Aloka Vision Program is part of the general eye camps performed by the eye doctors from the Himalayan Institute of Medical Sciences, Department of Ophthalmology. Study documents were in English language and explained in the local language. After registration participants were asked to fill a questionnaire on their educational level, their occupation, time spent outdoor, the status of spectacles correction, the awareness of vision care and the knowledge about healthy impact of ultraviolet radiation (UVR). Standardized protocol was followed by examinations from ophthalmologists in regards of anterior and posterior eye health. Possible eye conditions of pterygium [14] and cataract [15] were graded based on standard classification scales. Retinal fundus evaluation was performed using direct ophthalmoscopy and retinal abnormalities were graded by a trained ophthalmologist. After ophthalmological service, assessment of unaided visual acuity (VA), monocularly, using a printed eye chart with numbers or Tumbling E on a distance of 20 feet $(6 \mathrm{~m})$. Objective refraction for far vision was carried out using retinoscopy and was followed by a subjective refinement using a trial frame and trial lenses. Near vision test was performed in a distance of $40 \mathrm{~cm}$ to assess the additional power. For participants with uncorrected refractive error for far and/or near vision, a small selection of different optical frames was provided directly at the eye camp side. Later, glasses were produced by local opticians. In case of necessary surgery or further ophthalmological examination, participants were referred to the local ophthalmology clinic. Delivery of the glasses and transportation to the hospital was organized and carried out by local NGO partner.

\section{Statistical analysis}

For statistical analysis, the results from subjective refraction were transformed from sphere, cylinder and axis notation to their power vector components. [16] Frequency data on the incidence of uncorrected refractive error was calculated for the mean spherical refractive error $\mathrm{M}$ and classified as myopic for $\mathrm{M} \leq-0.5 \mathrm{D}$, as hyperopic for $\mathrm{M} \geq+0.5 \mathrm{D}$ and otherwise as emmetropic. Astigmatic refractive errors are considered as negative cylindrical errors Cyl $\leq-0.5 \mathrm{D}$. Visual acuity is transformed to a logarithmic scale (logMAR) and classified according to WHO scale1 as normal vision for $\mathrm{VA} \leq 0.0 \log \mathrm{MAR}$, mild and severe visual impairment for $0.5 \leq \mathrm{VA} \leq 1.3 \operatorname{logMAR}$ and as blindness for VA $>1.3 \log$ MAR. Analysis of eye health status and near vision needs were analyzed for participants aged $>40$ years $(N=270$ : Nurban $=134$, Nrural $=136)$. To analyze differences between the urban and the rural area, analysis of variance (ANOVA) was conducted for refraction and visual acuity data using the location as parameter. In case of categorical grading of diseases severeness and data from the questionnaire, differences were analyzed using the $\chi^{2}$-test. The significance level was set to $\alpha=0.05$. To determine the risk suffering from visual impairment, refractive error or ocular health conditions between the two screening locations, odd ratios were calculated. [17] All calculations were done in a matrix-based program (Matlab 2018a, Mathworks).

\section{Results}

A total number of 402 people were screened, including 191 participants in the urban and 211 participants in the rural area. $44 \%$ and $43 \%$ were male and $56 \%$ and $57 \%$ were female for the urban and rural area, respectively. Since the participation in the eye camp was open for all age classes, the age of participants ranged from 7 to 72 years and 7 to 80 years in the urban and rural area, respectively. Age frequency distribution for both eye camps locations are shown in Figure 2. 

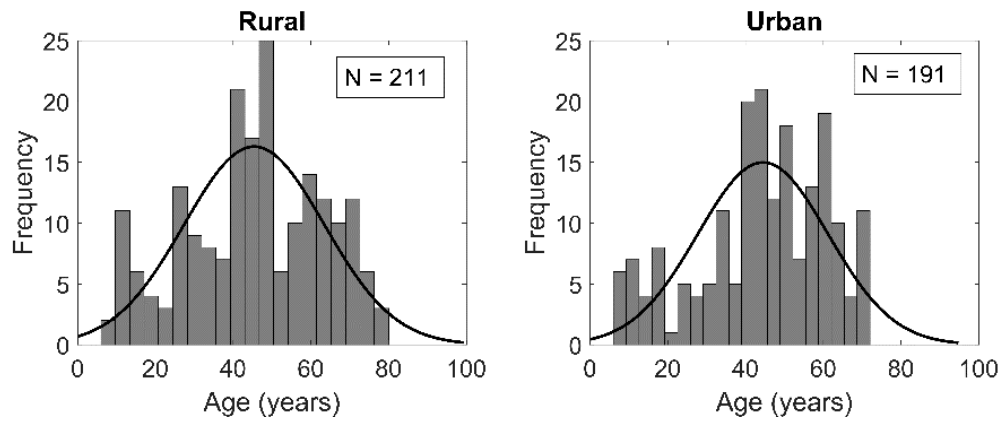

Figure 2: Age (years) distribution of eye camp locations in the urban (Dehradun) and rural (Mussoorie) area

\section{Eye healthy status}

Additionally, to the optometric examinations, measuring refractive errors and visual acuity, the medical integrity of the participants eyes was checked by an ophthalmologist. As shown in Table 1, frequency for pterygium and cataract was analyzed as two abnormal structural changes of the anterior eye segment and general abnormalities from the posterior segment. Frequency of pterygium and cataract, calculated for the entire screened population does not show a significant difference between the rural and urban area $\left(\chi^{2}=5.05, p=0.17 ; \chi^{2}=3.89, p=0.56\right)$. When analysis was performed only for participants aged older 40 years, no significant difference could be revealed $\left(\chi^{2}=0.27, p=\right.$ $\left.0.61 ; \chi^{2}=4.66, \mathrm{p}=0.45\right)$. The main cause of blindness for the study population was cataract $(\mathrm{n}=4,80$ $\%)$ followed by high myopia ( $\mathrm{n}=1,20 \%)$. Frequency of abnormalities from the fundus examination included conditions like exudates or drusen, vascular changes as retinal haemorrhage or glaucomatous changes of the optic disc. Living in a rural environment increased the risk of retinal abnormalities by 2.2 and 3.3 for the entire population and for the older population aged $>40$ years, respectively.

\section{Refractive error status}

Table 1 provides a summary of the frequency on the unaided visual acuity and the spherical equivalent refractive error for far vision. Worsening of unaided visual acuity was statistical significantly correlated with an increase in age $(r=0.43, p<0.01)$, although the explained variance was low $\mathrm{R} 2=0.18$. The difference in the mean spherical refractive error analyzed between the urban and rural area showed a small shift towards more negative values for the urban area $(\Delta M=0.26 \mathrm{D}$, $\mathrm{p}=0.11)$, but did not reach significance. Similar, the astigmatism components J0 and J45 were not significantly different between the urban and rural areas $\left(\mathrm{p}_{\mathrm{j} 0}=0.07, \mathrm{p}_{455}=0.68\right)$. When analyzing only ammetropic citizens $(\mathrm{N}=133)$ this shift towards more myopic refractive errors become more pronounced and clinically significant, but not statistically significant $(\Delta M=0.67 \mathrm{D}, \mathrm{p}=0.11)$. Following the measurements of the refractive errors of the eye for far and near vision, participants were asked to select an optical frame to be able to manufacture corrective glasses either for far, near or combined correction. In total, $63 \%$ and $61 \%$ of the people in rural and urban area were required to wear vision correction. 
medRxiv preprint doi: https://doi.org/10.1101/2020.10.27.20217000; this version posted November $1,2020$. The copyright holder for this preprint (which was not certified by peer review) is the author/funder, who has granted medRxiv a license to display the preprint in

perpetuity.
It is made available under a CC-BY 4.0 International license .

Table 1: Frequency data on unaided visual acuity (VA), type of refractive error (D) specified by the spherical equivalent (M) and ocular health for rural (Mussoorie) and urban (Dehradun) screening locations in north India. Odd ratios (OR) are calculated between the two locations

\begin{tabular}{|c|c|c|c|c|c|c|c|}
\hline & \multicolumn{2}{|c|}{ All n (\%) } & \multirow[t]{2}{*}{ OR } & \multicolumn{2}{|c|}{ Age $>40$ n (\%) } & \multirow[t]{2}{*}{ OR } \\
\hline & & Rural & Urban & & Rural & Urban & \\
\hline \multirow{3}{*}{ VA $(N=362)$} & Normal vision $(\mathrm{VA} \leq 0.0)$ & $99(53 \%)$ & $79(44 \%)$ & 1.01 & $50(40 \%)$ & $47(39 \%)$ & 1.08 \\
\hline & MSVI $(0.5 \leq$ VA $\leq 1.3)$ & $40(21 \%)$ & $38(21 \%)$ & 0.93 & $37(29 \%)$ & $30(24 \%)$ & 1.31 \\
\hline & Blind (VA > 1.3) & $4(2 \%)$ & $1(0.6 \%)$ & 3.89 & $3(2 \%)$ & $1(0.8 \%)$ & 3.00 \\
\hline \multirow{3}{*}{$\begin{array}{l}\text { Spherical } \\
\text { equivalent } \\
(\mathrm{N}=402)\end{array}$} & Hyperopia (M > $0.5 \mathrm{D})$ & $49(23 \%)$ & $40(21 \%)$ & 1.14 & $47(35 \%)$ & $37(28 \%)$ & 1.38 \\
\hline & Emmetropia $(\mathrm{M} \pm 0.5 \mathrm{D})$ & $142(67 \%)$ & $117(61 \%)$ & 1.30 & $76(56 \%)$ & $83(62 \%)$ & 2.89 \\
\hline & Myopia (M < $0.5 \mathrm{D})$ & $20(10 \%)$ & $34(18 \%)$ & 2.07 & $13(9 \%)$ & $14(10 \%)$ & 1.31 \\
\hline Astigmatism & Cylinder $\leq-0.5 \mathrm{D}$ & $25(12 \%)$ & $26(14 \%)$ & 1.17 & $18(13 \%)$ & $15(11 \%)$ & 1.21 \\
\hline \multirow{2}{*}{ Pterygium } & OD & $13(7 \%)$ & $6(3 \%)$ & 2.02 & $8(6 \%)$ & $9(7 \%)$ & 1.15 \\
\hline & OS & $10(5 \%)$ & $9(5 \%)$ & 1.01 & $6(5 \%)$ & $4(3 \%)$ & 1.50 \\
\hline \multirow{2}{*}{$\begin{array}{l}\text { Cataract } \\
(\mathrm{NOC}>1)\end{array}$} & OD & $26(14 \%)$ & $33(19 \%)$ & 1.48 & $24(19 \%)$ & $33(27 \%)$ & 1.52 \\
\hline & OS & $20(11 \%)$ & $32(18 \%)$ & 1.92 & $19(15 \%)$ & $32(26 \%)$ & 1.93 \\
\hline \multirow{2}{*}{ Retina } & No abnormalities & 202 (96\%) & 174 (91\%) & \multirow{2}{*}{2.20} & 205 (97\%) & $174(91 \%)$ & \multirow{2}{*}{3.30} \\
\hline & Abnormalities & $9(4 \%)$ & $17(9 \%)$ & & $6(3 \%)$ & $17(9 \%)$ & \\
\hline
\end{tabular}

Since not every medial or refractive conditions needs a treatment, analysis was further conducted for the frequency of referrals. As shown in Figure 3, four categories were analyzed: Prescription of glasses, cataract surgery, general referral to an eye hospital and no referral necessary. There was no significant different found between the rural and urban area in both age groups (All: $\chi^{2}=5.58, p=$ 0.13; Aged > 40: $\chi^{2}=3.81, p=0.28$ ). In general, Figure 3 reveals that a screening program aimed to discover uncorrected refractive errors would account for around $60 \%$ of the causes for visual impairment, whereas a pure ophthalmologic screening program would account for around $30 \%$ of the cases. A combined screening program of ophthalmology and optometry increases the number of discovered cases of visual impairment and enables to discover most cases suffering from eye health and vision conditions.
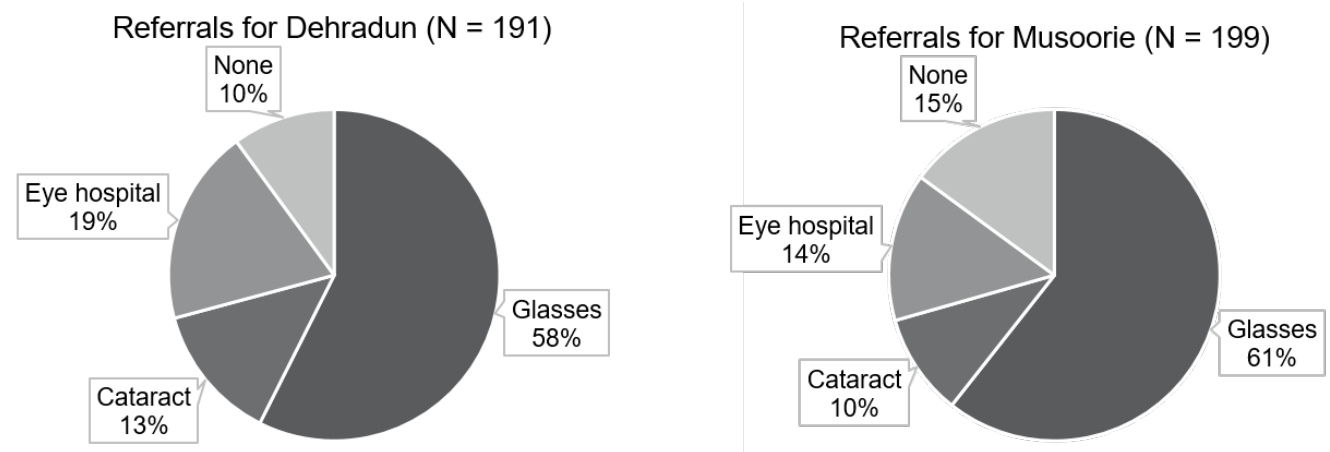

Figure 3: Frequency of different reasons for referral in the urban (Dehradun) and rural (Mussoorie) area 


\section{Need for refractive and non-refractive treatment in aged sub-population}

Presbyopia, the inability of near focusing of the crystalline lens, was analyzed for participants aged older 40 years ( $\mathrm{Nurban}=134$ and $\mathrm{N}_{\mathrm{Rural}}=136$ ). $84 \%$ of presbyopes required an additional power $\geq 1.0 \mathrm{D}$. Since there was no significant difference in age groups between the urban and rural area, no statistically significant difference could be found for the frequency and the amount of near addition power $(\triangle \mathrm{ADD}=-0.17 \mathrm{D}, \mathrm{p}=0.12)$.

The evaluation of the refractive error and the eye status for patients $>40$ years shows that, irrespective of pseudophakia or the possession of reading or distance glasses, only one of 247 was adequately supplied with near spectacles. This resulted in a frequency of $58 \%$ in the rural and $61 \%$ in the urban community which could be supplied with individually prescribed glasses. For $24 \%$ in the rural and $32 \%$ in the urban area, a medical treatment in the eye clinic followed by further prescription of glasses was arranged. For a group of $18 \%$ respectively $7 \%$ of the participants further dilated eye examination were required, the eye doctor's and optometrist's recommendation rejected by the person or as in case of retinal diseases no adequate medical treatment available. With a combined eye care approach, a treatment of individual vision correction or sight preservation treatments has been arranged for $90 \%$ while an optometry camp would have helped $60 \%$ only, or an ophthalmological camp $28 \%$ only.

\section{Cost estimations}

Although the majority of the participants suffer from uncorrected refractive error or treatable ocular health conditions (see Table 1), analysis of the results from the questionnaire (multiple answers possible) revealed that $64 \%$ in the urban area and $63 \%$ in the rural area cannot see a benefit in regular vision tests or eye exams. In terms of accessibility and affordability, $10 \%$ of people in the urban area further mention that vision care is not accessible, whereas in rural area accessibility was with $47 \%$ the second main reason not attending regular eye tests. Only $25 \%$ of people in the rural area were already wearing glasses, whereas the distribution of spectacles wear was with $36 \%$ slightly higher in the urban environment. $7 \%$ and $8 \%$ of the people from the rural and urban area, respectively, underwent eye surgery before the screening for various reasons. According the national Reserve bank India, the poverty line for 2012 for the state Uttarakhand is 880 ₹ ( 12\$) per month for the rural area and 1082 ₹ ( 14\$) per month for the urban area. Poverty (\% of people below poverty line) was shown to be significantly different $\left(\chi^{2}=24.79, \mathrm{p}<0.001\right)$ between the urban $(25 \%)$ and the rural area $(49 \%)$, respectively. Whereas the educational level is not significantly different $\left(\chi^{2}=3.41, \mathrm{p}=0.33\right)$.

The cost estimations for a four days inclusive eye camp are shown in Table 2. These costs represent the actual numbers from the reported camps and compromise next to the personal costs for the eye care experts and volunteers, the camp organization, the pre-promotion, people's mobilization, camp support from local volunteers and further the costs for the respective treatment like spectacles or cataract surgery based on frequency values given in Figure 3 . The major costs are given by the treatments $(58 \%)$, followed by mobilization and organization $(\sim 30 \%)$. The personal costs for the ophthalmologists and optometrist are low (11\%). 
Table 2: Cost estimation in k₹ for the pre-camp organization (4 days), completion (4 days) and treatment (4 days) of four days inclusive eye camps. The estimated numbers are based on the 400 screened people

\begin{tabular}{|c|c|c|c|c|c|c|c|c|}
\hline$\#$ & Description & Man power & & $\begin{array}{l}\text { Costs } \\
(\mathrm{k} ₹)\end{array}$ & Days & $\begin{array}{l}\text { Total } \\
(\mathrm{k} ₹)\end{array}$ & $\begin{array}{l}\text { Subtotal } \\
(\mathrm{k} ₹)\end{array}$ & $\begin{array}{c}\text { Subtotal } \\
(\%)\end{array}$ \\
\hline \multirow{2}{*}{1} & \multirow{2}{*}{$\begin{array}{l}\text { Personal costs } \\
\text { experts }\end{array}$} & Ophthalmologist & 1 & 4.85 & 4 & 19.40 & \multirow[b]{2}{*}{38.12} & \multirow[b]{2}{*}{$11.7 \%$} \\
\hline & & Optometrist & 4 & 1.17 & 4 & 18.72 & & \\
\hline \multirow{4}{*}{2} & \multirow{4}{*}{$\begin{array}{l}\text { Personal costs } \\
\text { volunteers }\end{array}$} & Pre-promotion & 4 & 0.50 & 4 & 8.00 & \multirow{4}{*}{20.00} & \multirow{4}{*}{$6.1 \%$} \\
\hline & & $\begin{array}{c}\text { Camp } \\
\text { mobilization }\end{array}$ & 2 & 0.50 & 4 & 4.00 & & \\
\hline & & Camp support & 2 & 0.50 & 4 & 4.00 & & \\
\hline & & $\begin{array}{l}\text { Distribution of } \\
\text { treatment }\end{array}$ & 2 & 0.50 & 4 & 4.00 & & \\
\hline \multirow{2}{*}{3} & \multirow{2}{*}{$\begin{array}{c}\text { Travel and } \\
\text { accommodation }\end{array}$} & Car rental/travel & 1 & 2.00 & 12 & 24.00 & \multirow[b]{2}{*}{64.00} & \multirow[b]{2}{*}{$19.6 \%$} \\
\hline & & KM flat rate & 400 & 0.025 & 4 & 40.00 & & \\
\hline 4 & Organization & & & & & 15.00 & 15.00 & $4.6 \%$ \\
\hline \multirow{3}{*}{5} & \multirow{2}{*}{ Treatment } & Spectacles $(60 \%)$ & 240 & 0.22 & & 52.80 & \multirow[b]{2}{*}{189.88} & \multirow[b]{2}{*}{$58.1 \%$} \\
\hline & & $\begin{array}{c}\text { Cataract surgery } \\
(10 \%)\end{array}$ & 40 & 3.43 & & 137.08 & & \\
\hline & & & & & Total & 327.00 & 327.00 & $100.0 \%$ \\
\hline
\end{tabular}

\section{Discussion}

The current study reports on a combined case-finding screening program in north India, Uttarakhand. Overall, the results reveal that a screening program aimed to discover uncorrected refractive errors would account for around $60 \%$ of the causes for visual impairment, whereas a pure ophthalmologic screening program would account for around $30 \%$ of the cases.

\section{Frequency of visual impairment and blindness}

Visual impairment is classified by the WHO as visual acuity below $6 / 18$ but above 3/60.[4] For visual acuity below 3/60 the person is classified as blind. Apart from the resolution performance of an eye, measured as the visual acuity, the functional visual field can be examined and is defined, in case of blindness as below $10^{\circ}$. The frequency reported from the current study on the visual impairment $\sim 20 \%$ for rural and urban area in north India are higher as compared to the literature. The main reason for this is that the currently investigation is not a population-based study, since the no random cluster strategies are applied. However, Studies which were based on these random assignments found prevalence of $8 \%$ [18], $10 \%$ [19] and $2 \%$ [20] of mild and server visual impairment among southern, western and north Indian populations, respectively. However, prevalence data can vary between different states, since a population-based survey from Murthy et al. (2005) in Gujarat, northwestern India, revealed a prevalence of visual impairment of $29 \%$.[5] The current screening program design results in a higher frequency of visual impairment findings due to the general openness of the program without any preliminary selection. Therefore, the likelihood for people without having subjective visual problems to join such screening programs is lower compared to people have visual complains. Dandona et al. (2002) conducted the Andhra Pradesh Eye Disease Study on 12,000 people from southern India and revealed that living in a rural area having a statistically significant higher odd as living in an urban area (odds ratio 2.12) to suffer from moderate visual impairment.[18] The current study revealed a higher odd only for the age group $>40$ years, while this was associated with a higher risk for blindness when living in the rural area. The global 
trend of increased prevalence in urban environments of myopic refractive error, mainly studied in school children [21-23], can be confirmed in the current study (odds ratio 2.1), when analyzing the entire study population aged from 7 to 80 years.

Previous studies conducted rapid assessment of avoidable blindness (RAAB) for different countries in the world and revealed prevalence of blindness ranged from $1 \%$ to $8 \%$.[24-27] Prevalence of blindness estimated from the current study for north India, showed comparable values and a higher risk for blindness in rural areas. due to the small sample size, the absolute numbers of blindness are low. The difference between the living environments is confirmed by previous findings from Patil et al. (2014).[19] There the prevalence of blindness was with $1.8 \%$ significantly higher in rural areas in western India than in urban areas. This trend was shown also for other regions in the world like Indonesia [28], China [22] or Pakistan.[29] Globally, the main cause of blindness is cataract [1], as confirmed by the current study also for north India. Additionally, the age, higher life time exposure to UVR might be associated with an increased risk for cataract.[30-33] Furthermore, it is expectable that the combination of rural living environment, more time spent outdoors and higher altitude associated with higher UVR exposure [34] leads to an increase in UV-related eye disease like pterygium and senile cataract. However, odds from the current study showed only a slight increase of risk. A possible explanation is that UVR level can vary between urban and rural environments due to differences in the albedo between city surfaces and for instant grass or soil areas in rural areas. [35-38] A second reason for an elevated risk, specifically for cataract in the urban area, can be an economical one. Main reason for no eye care was affordability in the urban area. This is contradictory to the finding of BPL. However, the reported frequencies have to be interpreted cautiously since the current study design was an opportunistic screening and no cross-sectional population-based study.

\section{Socio-economic benefits of inclusivity of ophthalmology and optometry in vision screening programs}

Assuming that the organizational parts in separated screening programs for eye health or vision care keeps similar, Table 2 shows that the travel expenses and costs for mobilization and coordination represent the largest share and therefore a combined eye and vision care program has a higher costefficiency.

The World Health Organization's Vision 2020 program emphasizes to "strive to make refractive services and corrective spectacles affordable and available to the majority of the population through primary health care facilities, vision screening in schools and low-cost production of spectacles".[4] Besides the fact that patients appreciate restoring of sight regardless ophthalmological treatment or providing glasses suits their needs, a cost efficiency ratio speaks for inclusion of eye and vision care as the major pool of costs (mobilization, local support, travel) can be spared by combining screening for refractive as for non-refractive errors and visual impairments.

Models for primary eye care in India utilize different aspects of vision screenings, covering for instance vision centers through permanent infrastructure $[39,40]$ mobile units including screening and treatment abilities [7,9] or a combination of both.[6] One remarkable aspect of providing vision and eye care in unserved, rural and urban areas, is the patient satisfaction. In a review article Misra et al. (2015) pointed out that one important feature to satisfaction is the accessibility and the associated traveling costs.[6] Considering the fact that the next screening facility would require hourlong travel and, as the majority of workers in rural areas are day-laborers, the loss of a day income the expenses sum up to ₹850-₹1,000, compared to ₹220 for complete Aloka pair of spectacles including vision test.

The assessment of the refractive errors of an eye can lead to the treatment of the most prevalent cause for visual impairment.1 Data from the current study show that the spectacles coverage is higher in urban than in rural areas, which is in line with finding for other countries like Kenya [41], Bangladesh [42] or Australia.[43] This is mainly explained by the higher density of optical stores in cities. The finding from the current study, that there is no difference in the distribution of refractive error, but a lack of accessibility to corrective glasses, underlines the need of inclusive ophthalmological and optometrical vision care programs. Providing spectacles in unserved areas was 
shown previously to be a cost effectiveness intervention [44] for India [45] and other regions in the world.[46] Hereby, the costs of fitting and dispensing spectacle vary between studies and are estimated with US\$5.0 [47] to US\$25.0 [45], depending on the country. A RAAB from Marmamula, Keeffe and Rao (2009) in the district of Andhra Pradesh, India, revealed an unmet need for the correction of refractive errors for far and near vision.[48] The authors conclude that a delivery model like it provided by the vision centers $[39,40]$ in conjunction with local optical outlets could serve as a successful vision care service. The training of local entrepreneurs within the scope of the Aloka Vision Programme and the results on the current frequency numbers on visual conditions enable a better effectiveness of spectacles coverage in urban and rural areas.

Cataract as leading cause of blindness worldwide1 represents a treatable eye health condition which deteriorates vision by the clouding of crystalline lens. Cataract surgical rate (CSR) was set by the Global Action Plan 2013 from the WHO as one core indicator for the access to cataract services in a country.[49] Wang et al. (2016) analyzed CSR from 152 countries and showed that there is a linear relationship between CSR and the gross domestic product per capita of a country.[50] The data for India shows a higher CSR as expected from the model and an increase in CSR from 4,800 to 6,000 in the years from 2009 to 2014 showing that the access to cataract service raised for the last years. Besides the availability of health care, these procedures have to be affordable by the people. For different regions in the world, cataract surgery was shown to be a cost-effective procedure to restore vision, 51 but cost-Utility (\$ / QALY, Dollar per quality adjusted life year) depends strongly on the individual country. In western countries like the United states, the cost-utility for cataract surgery is 2,020 US\$ / QALY [51,52], whereas cost-utility for India is 8.07 US\$ / QALY.[51,53] Comparing cost utility numbers with the willingness-to-pay showing that cataract surgery is an affordable treatment also in developing countries.

\section{Conclusions}

To conclude, the current study reports on a case-finding screening program as a combination of mobile examinations and hospital-based treatment referrals. Frequency of eye conditions showed that uncorrected refractive error account for most of visual impairments, which could be costeffectively treated by spectacles fitting. A holistic approach providing combined ophthalmology and optometry examinations combined with a mobile screening camp and a well-organized referral coordination by local NGOs, private companies and local health partners, can provide an increase effectiveness for vision and eye care services in rural and urban areas in Uttarakhand.

Author Contributions: Conceptualization, S.W., A.L., R.D., P.M., N.S. and J.K.; methodology, S.W., A.L. and R.D.; formal analysis, S.W. and A.L.; investigation, S.W., A.L., R.D., P.M.,V.K.K., N.S. and J.K.; resources, S.W., R.D. and J.K.; data curation, A.L.; writing-original draft preparation, A.L.; writing-review and editing, S.W., A.L., R.D., P.M.,V.K.K., N.S. and J.K.; All authors have read and agreed to the published version of the manuscript.

Funding: This research was supported by Deutsche Forschungsgemeinschaft (ZUK63).

Acknowledgments: We would like to thank V. Kumar from Carl Zeiss India Pvt. Ltd, Nitin Sisodi from Sohum Innovation Lab, Parvitya Jan Kalyan Sansthan as non-governmental organization for the local organization and Petra Apelt from the Carl Zeiss Vision International GmbH for their continuous support. The ophthalmological examinations were performed by Dr. Shweta Sharma and Dr. Nishtha Yadav from the Department of Ophthalmology, Himalayan Institute of Medical Science. We further thank all participants for being part of this screening program.

Conflicts of Interest: S. Wahl and A. Leube are scientists at the University Tuebingen. S. Wahl, A. Leube and J. Kuss are employees of Carl Zeiss Vision International GmbH. P. Moodbidri is employee of Carl Zeiss India Pvt. Ltd. R. Dhasmana is an ophthalmologist at the Himalayan Institute of Medical Science. 
medRxiv preprint doi: https://doi.org/10.1101/2020.10.27.20217000; this version posted November 1,2020 . The copyright holder for this preprint (which was not certified by peer review) is the author/funder, who has granted medRxiv a license to display the preprint in

perpetuity.
It is made available under a CC-BY 4.0 International license .

\section{References}

1. Pascolini D, Mariotti SP. Global estimates of visual impairment: 2010. Br J Ophthalmol 2012;96:614-618.

2. Foster A, Resnikoff S. The impact of Vision 2020 on global blindness. Eye 2005;19:1133.

3. Neilsen De Souza YC, Looi S, Paudel P, et al. The role of optometrists in India: An integral part of an eye health team. Indian J Ophthalmol 2012;60:401.

4. World Health Organization. Programme for the Prevention of Blindness and Deafness. Global initiative for the elimination of avoidable blindness. 2000.

5. Murthy GVS, Gupta SK, Bachani D, et al. Current estimates of blindness in India. Br J Ophthalmol 2005;89:257-260.

6. Misra V, Vashist P, Malhotra S, et al. Models for primary eye care services in India. Indian J community Med Off Publ Indian Assoc Prev Soc Med 2015;40:79.

7. Sharma M, Chakrabarty AS, Pavan R, et al. An integrated, mobile service for diabetic retinopathy in rural India. Community Eye Heal 2011;24:17.

8. Bai VT, Murali V, Kim R, et al. Teleophthalmology-based rural eye care in India. Telemed e-Health 2007;13:313-321.

9. John S, Sengupta S, Reddy SJ, et al. The Sankara Nethralaya mobile teleophthalmology model for comprehensive eye care delivery in rural India. Telemed e-Health 2012;18:382-387.

10. Paul PG, Raman R, Rani PK, et al. Patient satisfaction levels during teleophthalmology consultation in rural South India. Telemed J e-Health 2006;12:571-578.

11. Rachapelle S, Legood R, Alavi Y, et al. The cost-utility of telemedicine to screen for diabetic retinopathy in india. Ophthalmology 2013;120:566-573.

12. Garg P, Reddy S, Nelluri C. Training the eye care team: principles and practice. Middle East Afr J Ophthalmol 2014;21:128.

13. Wilson JMG, Jungner G. Principles and practice of screening for disease. Public Heal Pap - World Heal Organ 1968;34:7-151.

14. Johnston SC, Williams PB, Sheppard JD. A comprehensive system for pterygium classification. Invest Ophthalmol Vis Sci 2004;45:2940.

15. Chylack LT, Wolfe JK, Singer DM, et al. The lens opacities classification system III. Arch Ophthalmol 1993;111:831-836.

16. Thibos LN, Wheeler W, Horner D. Power vectors: an application of Fourier analysis to the description and statistical analysis of refractive error. Optom Vis Sci 1997;74:367-375.

17. McHugh ML. The odds ratio: calculation, usage, and interpretation. Biochem medica Biochem medica 2009;19:120-126.

18. Dandona R, Dandona L, Srinivas M, et al. Moderate visual impairment in India: the Andhra Pradesh eye disease study. Br J Ophthalmol 2002;86:373-377.

19. Patil S, Gogate P, Vora S, et al. Prevalence, causes of blindness, visual impairment and cataract surgical services in Sindhudurg district on the western coastal strip of India. Indian J Ophthalmol 2014;62:240.

20. Malhotra S, Vashist P, Gupta N, et al. Prevalence and causes of visual impairment among adults aged 1549 years in a rural area of north India-A population-based study. Indian J Ophthalmol 2018;66:951.

21. Uzma N, Kumar BS, Salar BMKM, et al. A comparative clinical survey of the prevalence of refractive errors and eye diseases in urban and rural school children. Can J Ophthalmol 2009;44:328-333.

22. $\mathrm{Xu} \mathrm{L}$, Li J, Cui T, et al. Refractive error in urban and rural adult Chinese in Beijing. Ophthalmology 2005;112:1676-1683.

23. Murthy GVS, Gupta SK, Ellwein LB, et al. Refractive error in children in an urban population in New Delhi. Invest Ophthalmol Vis Sci 2002;43:623-631.

24. Mathenge W, Kuper H, Limburg H, et al. Rapid assessment of avoidable blindness in Nakuru district, Kenya. Ophthalmology 2007;114:599-605.

25. Oye JE, Kuper H. Prevalence and causes of blindness and visual impairment in Limbe urban area, South West Province, Cameroon. Br J Ophthalmol 2007;91:1435-1439.

26. Chiang F, Kuper H, Lindfield R, et al. Rapid assessment of avoidable blindness in the Occupied Palestinian Territories. PLoS One 2010;5:e11854.

27. Neena J, Rachel J, Praveen V, et al. Rapid assessment of avoidable blindness in India. PLoS One 2008;3:e2867. 
medRxiv preprint doi: https://doi.org/10.1101/2020.10.27.20217000; this version posted November 1,2020 . The copyright holder for this preprint (which was not certified by peer review) is the author/funder, who has granted medRxiv a license to display the preprint in

perpetuity.
It is made available under a CC-BY 4.0 International license.

28. Saw SM, Husain R, Gazzard GM, et al. Causes of low vision and blindness in rural Indonesia. Br J Ophthalmol 2003;87:1075-1078.

29. Dineen B, Bourne RRA, Jadoon Z, et al. Causes of blindness and visual impairment in Pakistan. The Pakistan national blindness and visual impairment survey. Br J Ophthalmol 2007;91:1005-1010.

30. Balasubramanian D. Ultraviolet radiation and cataract. J Ocul Pharmacol Ther 2000;16:285-297.

31. Hollows F, Moran D. Cataract-the ultraviolet risk factor. Lancet 1981;318:1249-1250.

32. Taylor HR, West SK, Rosenthal FS, et al. Effect of ultraviolet radiation on cataract formation. N Engl J Med 1988;319:1429-1433.

33. Cruickshanks KJ, Klein BE, Klein R. Ultraviolet light exposure and lens opacities: the Beaver Dam Eye Study. Am J Public Health 1992;82:1658-1662.

34. Blumthaler M, Ambach W, Ellinger R. Increase in solar UV radiation with altitude. J Photochem Photobiol B Biol 1997;39:130-134.

35. Heisler GM. Health impacts of ultraviolet radiation in urban ecosystems: a review. In: Ultraviolet Groundand Space-based Measurements, Models, and Effects V. International Society for Optics and Photonics 2005. 58860M.

36. Prado RTA, Ferreira FL. Measurement of albedo and analysis of its influence the surface temperature of building roof materials. Energy Build 2005;37:295-300.

37. Castro T, Mar B, Longoria R, et al. Surface albedo measurements in Mexico City metropolitan area. Atmósfera 2001;14:69-74.

38. Heisler GM. Urban forest influences on exposure to UV radiation and potential consequences for human health. In: UV Radiation in Global Climate Change. Springer 2010. 331-369.

39. Jose R, Rathore AS, Rajshekar V, et al. Salient features of the National Program for Control of Blindness during the XIth five-year plan period. Indian J Ophthalmol 2009;57:339.

40. Rao GN, Khanna RC, Athota SM, et al. Integrated model of primary and secondary eye care for underserved rural areas: the LV Prasad Eye Institute experience. Indian J Ophthalmol 2012;60:396.

41. Bastawrous A, Mathenge W, Foster A, et al. Prevalence and predictors of refractive error and spectacle coverage in Nakuru, Kenya: a cross-sectional, population-based study. Int Ophthalmol 2013;33:541-548.

42. Bourne RRA, Dineen BP, Huq DMN, et al. Correction of refractive error in the adult population of Bangladesh: meeting the unmet need. Invest Ophthalmol Vis Sci 2004;45:410-417.

43. Keeffe JE, Weih LM, McCarty CA, et al. Utilisation of eye care services by urban and rural Australians. Br J Ophthalmol 2002;86:24-27.

44. Holden BA. The Role Of Optometry In Vision 2020. Community Eye Heal 2002;15.

45. Frick KD, Riva-Clement L, Shankar MB. Screening for refractive error and fitting with spectacles in rural and urban India: cost-effectiveness. Ophthalmic Epidemiol 2009;16:378-387.

46. Baltussen R, Naus J, Limburg H. Cost-effectiveness of screening and correcting refractive errors in school children in Africa, Asia, America and Europe. Health Policy (New York) 2009;89:201-215.

47. Lester BA. Comparing the cost-effectiveness of school eye screening versus a primary eye care model to provide refractive error services for children in India. Community Eye Heal 2007;20:15.

48. Marmamula S, Keeffe JE, Rao GN. Uncorrected refractive errors, presbyopia and spectacle coverage: results from a rapid assessment of refractive error survey. Ophthalmic Epidemiol 2009;16:269-274.

49. World Health Organization. Universal eye health: a global action plan 2014-2019. World Heal. Organ. 2018.https://www.who.int/blindness/actionplan/en/ (accessed 22 Feb 2019).

50. Wang W, Yan W, Fotis K, et al. Cataract surgical rate and socioeconomics: a global study. Invest Ophthalmol Vis Sci 2016;57:5872-5881.

51. Lansingh VC, Carter MJ, Martens M. Global cost-effectiveness of cataract surgery. Ophthalmology 2007;114:1670-1678.

52. Busbee BG, Brown MM, Brown GC, et al. Incremental cost-effectiveness of initial cataract surgery. Ophthalmology 2002;109:606-612.

53. Gogate PM, Deshpande M, Wormald RP. Is manual small incision cataract surgery affordable in the developing countries? A cost comparison with extracapsular cataract extraction. Br J Ophthalmol 2003;87:843-846. 